\title{
COMPARATIVE ANALYSIS OF PHYTOCHEMICAL, ANTIBACTERIAL, AND ANTIOXIDANT ACTIVITY OF DIFFERENT EXTRACTS OF AZADIRACHTA INDICA LEAVES
}

\author{
GAURAV SHARMA*, ANKITA THAKUR, SOHAN LAL, ROHIT KUMAR NADDA
}

Department of Biotechnology, Faculty of Applied Sciences and Biotechnology, Shoolini University, Solan, Himachal Pradesh, India. Email: dr.gorav143@gmail.com

Received: 23 August 2018, Revised and Accepted: 6 December 2018

\section{ABSTRACT}

Objective: The objective of the present study was the analysis of phytochemicals in various extracts of Azadirachta indica leaves, comparative evaluation of antibacterial activity of the various extracts of A. indica leaves against Escherichia coli and Staphylococcus aureus, and comparative evaluation of antioxidant activity in various extracts of $A$. indica leaves using 1, 1-diphenyl-2-picrylhydrazyl (DPPH) radical scavenging assay.

Methods: Various extracts were prepared by crushing the samples. Antibacterial susceptibility test, various phytochemical tests for qualitative analysis, and DPPH radical scavenging assay for antioxidant activity were performed.

Results: The result suggested that alkaloids, flavonoids, and terpenoids were present in all the four extracts. Tannins were absent in the ethyl acetate extract, and phenols were only present in the ethyl acetate extract. Sterols and phlobatannins were absent in all the four extracts. Saponins were only present in the aqueous extract, and amino acids were only present in the ethyl acetate extract. The bacterial strains $S$. aureus and E. coli were used against the different extracts of $A$. indica leaves, i.e., methanol, chloroform, ethyl acetate, and aqueous.

Conclusion: The results suggested that bioactive compounds found in leaves of $A$. indica contribute to its pharmacological activities.

Keywords: Antioxidant activity, 1, 1-Diphenyl-2-picrylhydrazyl, Radical assay, Triterpenoids, Ninhydrin.

(C) 2019 The Authors. Published by Innovare Academic Sciences Pvt Ltd. This is an open access article under the CC BY license (http://creativecommons. org/licenses/by/4. 0/) DOI: http://dx.doi.org/10.22159/ajpcr.2019.v12i3.29286

\section{INTRODUCTION}

Azadirachta indica is a fast growing evergreen popular tree found commonly in India, Africa, and America [1]. It has been used in Ayurvedic medicine for $>4000$ years due to its medicinal properties. Neem is called "arista" in Sanskrit, a word that means "perfect," complete, and imperishable [2]. The tree is regarded as "village dispensary" in India. Each part of the neem tree has some medicinal property and is thus commercially exploitable. Several pharmacological activities and medicinal applications of various parts of neem are well known. Although large numbers of compounds have been isolated from various parts, a few have been studied for biological activity. Nimbidin, a major crude bitter principle extracted from the oil of seed kernels of $A$. indica, demonstrated several biological activities. Two polymers isolated from neem bark possess anti-complement activity among which the compound NB-II, a peptidoglycan of lower molecular weight, was found to be more potent. A significant antiulcer effect was observed with nimbidin in preventing acetylsalicylic acid, indomethacin, stress, or serotonin-induced gastric lesion as well as histamine or cysteamineinduced duodenal ulcers. Nimbidin can also suppress basal as well as histamine and carbachol-stimulated gastric acid output and may act as an antihistamine by blocking hydrogen receptors, thereby helping as an antiulcer agent. The spermicidal activity of nimbidin and nimbin was reported in rats and human as early as 1959. From this crude principle, some tetranortriterpenoids, including nimbin, nimbinin, nimbidinin, nimbolide, and nimbidic acid, have been isolated. Nimbidin and sodium nimbidate possess significant dose-dependent antiinflammatory activity against carrageenin-induced acute paw edema in rats and formalin-induced arthritis [3]. Antipyretic activity has also been reported and confirmed in nimbidin. Oral administration of nimbidin demonstrated a significant hypoglycemic effect in fasting rabbits. Phytosterol fraction, an active ingredient isolated from the lipid part of neem fruits, exhibits antiulcer activity in stress-induced gastric lesions [4]. The present study was the analysis of phytochemicals in various extracts of $A$. indica leaves, comparative evaluation of antibacterial activity of various extracts of $A$. indica leaves against Escherichia coli and Staphylococcus aureus, and comparative evaluation of antioxidant activity in various extracts of $A$. indica leaves using 1 , 1-diphenyl-2-picrylhydrazyl (DPPH) radical scavenging assay.

\section{Plant authentication}

Plant authentication was done at Dr. Y.S. Parmar University of Horticulture and Forestry under the Herbarium No. - 1015.

\section{MATERIALS AND METHODS}

Materials

A. indica leaves were collected from Bilaspur district of Himachal Pradesh, India.

\section{Preparation of the aqueous extract}

The aqueous extract was prepared according to Sripanidkulchai et al., with the slight changes. $5 \mathrm{~g}$ of $A$. indica powder was boiled in $80 \mathrm{ml}$ distilled water for 2-3 h. The solution was filtered through a Whatman filter paper, and the filtrate was collected in a Petri dish. The filtrate was evaporated by heating over the hot plate at a temperature of $60^{\circ} \mathrm{C}$ for 2-3 h. The weight of the crude extract was recorded. The crude extract was dissolved in the dimethyl sulfoxide (DMSO) at the concentration of $100 \mathrm{mg} / \mathrm{ml}$

Bacterial strains and antibiotic used two bacterial strains were used in this study - one Gram-positive ( $S$. aureus) and one Gram-negative (E. coli). Both the strains were obtained from Yeast Biology Lab, Shoolini University, Solan. Pure cultures were maintained on NA plates and stored at $4^{\circ} \mathrm{C}$. Ampicillin $(100 \mu \mathrm{g} / \mathrm{ml})$ was used in this study.

\section{Phytochemical tests (qualitative analysis)}

Detection of phenolic (ferric chloride test) extracts was treated with 3-4 drops of $5 \%$ ferric chloride solution. The appearance of bluish 
or greenish-black coloration indicates the presence of pyrogallol or catechol tannins. Formation of a bluish black color indicates the presence of phenols.

\section{Detection of flavonoids (lead acetate test)}

Extracts were treated with few drops of $10 \%$ lead acetate solution. Formation of yellow color precipitate indicated the presence of flavonoids.

\section{Detection of carbohydrates (Fehling's test)}

Extracts were treated with 2-3 drops of Fehling's reagent and heated to $10 \mathrm{~min}$. The appearance of red color precipitate indicated the presence of reducing sugars.

\section{Detection of alkaloids (Mayer's Test)}

Extracts were dissolved individually in dilute hydrochloric acid and filtered. Filtrates were treated with 2-3 drops of Mayer's reagent (potassium mercuric iodide). Formation of a yellow-colored precipitate indicated the presence of alkaloids.

Detection of Proteins (Millon's test) and amino acids (xanthoproteic test)

For proteins

About $20 \mu \mathrm{l}$ of million reagents were added to the test tube containing $1 \mathrm{ml}$ of extract and then heated in the water bath for $10 \mathrm{~min}$. The samples were cooled and $10 \mu \mathrm{l}$ of $1 \%$ sodium nitrite solution was added to the samples.

For amino acids

To $1 \mathrm{ml}$ of extract, added $4-5$ drops of $0.1 \%$ ninhydrin solution. Purple color indicated the presence of amino acids.

\section{Detection of triterpenoids (Salkowski's test)}

Extracts were treated with chloroform and filtered. The filtrates were treated with few drops of concentrated sulfuric acid, shaken, and allowed to stand. The appearance of golden yellow color indicated the presence of triterpenes.

\section{Antioxidant activity (DPPH radical scavenging assay)}

The DPPH radical scavenging assay of various extracts of $A$. indica was conducted. In this method, $900 \mu \mathrm{l}$ of $0.1 \mathrm{mM}$ DPPH solution (prepared in ethanol) was mixed with $100 \mu \mathrm{l}$ of methanolic, ethyl acetate, chloroform, and aqueous extracts of $A$. indica ranging from $2.5 \mu \mathrm{g} / \mathrm{ml}$ to $20 \mu \mathrm{g} / \mathrm{ml}$. The reaction mixture was shaken and incubated in the dark at room temperature for $30 \mathrm{~min}$, and the absorbance was read at $517 \mathrm{~nm}$ against the blank. Ascorbic acid was used as the standard. DPPH radical scavenging activity was calculated from the following equation:

DPPH radical scavenging activity $(5)=1-A_{s} / A_{c} \times 100$

Where $A_{c}$ - Absorbance of control and $A_{s-}$ Absorbance of the test sample.

\section{RESULTS AND DISCUSSION}

\section{Extract yield}

For aqueous extract preparation, $5 \mathrm{~g}$ of $A$. indica leaf powder was boiled in $80 \mathrm{ml}$ distilled water for $2-3 \mathrm{~h}$. The solution was filtered and the filtrate was evaporated by heating over the hot plate at a temperature of $60^{\circ} \mathrm{C}$ for $2-3 \mathrm{~h}$. The weight was recorded. For methanol, chloroform, and ethyl acetate, $10 \mathrm{~g}$ of $A$. indica leaf powder was added into $150 \mathrm{ml}$ solvents and kept at shaker for 3-4 days. The solutions were then filtered, and the filtrate was evaporated in the incubator at $37^{\circ} \mathrm{C}$ temperature for $24 \mathrm{~h}$. The extracts were prepared, and their weight was recorded and stored at $4^{\circ} \mathrm{C}$. The yield obtained of the different extracts is shown in Table 1. The result showed that the yield of ethyl acetate extract was higher than other extracts. It may be due to the different polarities of the solvents used (Fig. 1).
Table 1: Percentage yield of different extracts of Azadirachto indica leaves

\begin{tabular}{llll}
\hline S. No & Extracts & $\begin{array}{l}\text { Weight of } \\
\text { extracts } \mathbf{( m g )}\end{array}$ & $\begin{array}{l}\text { Percentage } \\
\text { yield (\%) }\end{array}$ \\
\hline 1 & Aqueous & 95 & 1.9 \\
2 & Methanol & 200 & 2 \\
3 & Chloroform & 60 & 0.6 \\
4 & Ethyl acetate & 530 & 5.3 \\
\hline
\end{tabular}

Maximum yield was obtained with ethyl acetate followed by methanol and water

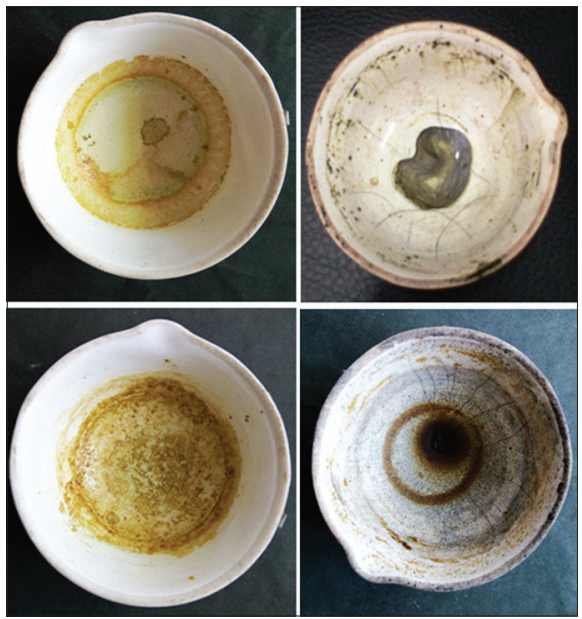

Fig. 1: Extracts of Azadirachta indica leaves: (a) Methanol extract, (b) chloroform extract, (c) ethyl acetate extract, (d) aqueous extract

Analysis of phytochemicals in various extracts of $\boldsymbol{A}$. indica leaves The screening of phytochemicals was done in all the four extracts by performing various tests.

\section{Test for phenolics}

The ferric chloride test formation of greenish black color revealed that phenolics were present in the methanol, ethyl acetate, and aqueous extracts. The chloroform extract did not reveal the presence of phenolics.

\section{Tests for flavonoids}

In the lead acetate test, formation of yellow precipitate revealed that flavonoids are present in all the extracts. The control contains lead acetate. The yellow color precipitation was detected in all the extracts.

\section{Test for carbohydrates}

Fehling's test for carbohydrates revealed the presence of reducing sugars in aqueous, methanol, and ethyl acetate extracts, whereas chloroform extract showed the absence of carbohydrate. Formation of green or red color indicated the presence of reducing sugar.

\section{Test for alkaloids}

Mayer's test for alkaloids revealed that aqueous, methanol, chloroform, ethyl acetate, and crude methanol shows the presence of alkaloids. Other than the aqueous, methanolic, chloroform and ethyl acetate there is also another solution (A) which is marked as Control and consists only reagent. In all extracts, yellow color precipitate or turbidity was observed. Formation of yellow color indicated the presence of alkaloids.

\section{Ninhydrin test}

Formation of yellow color in the ethyl acetate extract revealed the presence of amino acids. The control contains the concentrated $\mathrm{HNO}_{3}$. 
Table 2: Phytochemical constituents present in different extracts of Azadirachta indica leaves

\begin{tabular}{lllll}
\hline Phytocompound & Test & $\begin{array}{l}\text { Methanol } \\
\text { extracts }\end{array}$ & $\begin{array}{l}\text { Chloroform } \\
\text { extracts }\end{array}$ & $\begin{array}{l}\text { Aqueous } \\
\text { extracts }\end{array}$ \\
\hline Phenolic & FeCl $_{3}$ test & + & - & + \\
Flavonoids & Lead acetate test & + & + & + \\
Carbohydrate & Fehling's test & + & + & + \\
Proteins/amino acids & Ninhydrin test & - & - & + \\
& Millon's test & - & - & - \\
Alkaloids & Dragendorff's test & + & + & + \\
Terpenoids & Salkowski's test & + & + & + \\
\hline
\end{tabular}

Table 3: Comparative antibacterial activity of different extracts of the leaves of Azadirachta indica

\begin{tabular}{lll}
\hline Plant extract & \multicolumn{2}{l}{ Zone of inhibition $(\mathbf{m m})$} \\
\cline { 2 - 3 } & $\begin{array}{l}\text { Staphylococcus } \\
\text { aureus }\end{array}$ & $\begin{array}{l}\text { Escherichia } \\
\text { coli }\end{array}$ \\
\hline Methanol extract & $19.5 \pm 0.707107$ & $18.5 \pm 0.707107$ \\
Chloroform extract & 0 & 0 \\
Ethyl acetate extract & $11.5 \pm 0.707107$ & $10.5 \pm 0.707107$ \\
Aqueous extract & $13 \pm 1.414214$ & $9.5 \pm 0.707107$ \\
Positive control (ampicillin) & 30 & 10 \\
Negative control (solvent) & 0 & 0 \\
\hline
\end{tabular}

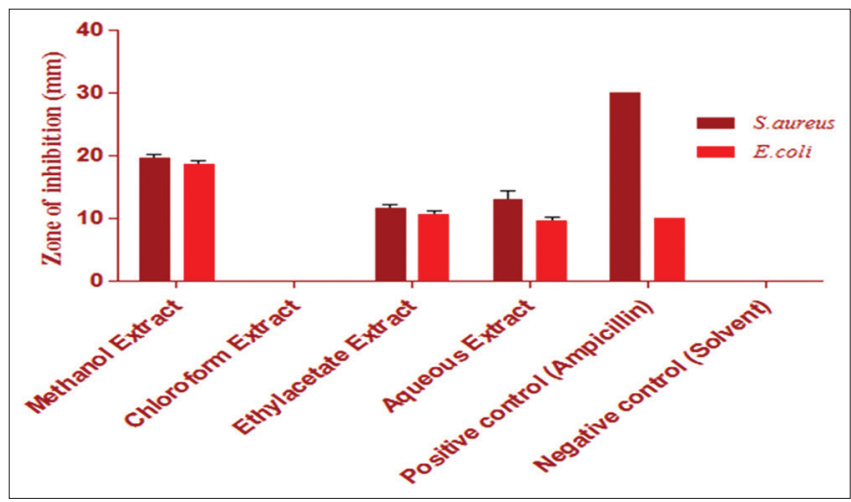

Fig. 2: The comparative antibacterial activity of different extracts of Azadirachta indica leaves

The yellow color was absent in the aqueous, methanol, and chloroform extract, showing the absence of amino acids.

\section{Tests for triterpenoids}

In Salkowski's test, the formation of reddish-brown color revealed that triterpenoids were present in all the extracts. It contains chloroform in Control-1 and concentrated $\mathrm{H}_{2} \mathrm{SO}_{4}$ in control-2. The reddish brown color was formed in the aqueous, methanol, chloroform and ethyl acetate extract of $A$. indica leaves (Table 2).

The result showed that various phytochemicals were present in the aqueous, methanol, chloroform, and ethyl acetate extract. Alkaloids, flavonoids, and terpenoids were present in all the four extracts. Tannins were absent in the ethyl acetate extract, and phenols were only present in the ethyl acetate extract. Sterols and phlobatannins were absent in all the four extracts. Saponins were only present in the aqueous extract, and amino acids were only present in the ethyl acetate extract. "++" indicates the more intense color as compared to other extracts.

Comparative evaluation of antibacterial activity of various extracts of $A$. indica leaves against $E$. coli and $S$. aureus

The antimicrobial activity of different extracts of $A$. indica was tested against the $S$. aureus and E. coli bacteria. The zone of inhibition against $S$. aureus was $19.5 \mathrm{~mm}$ for methanol extract, $11.5 \mathrm{~mm}$ for ethyl acetate extract, and of $13 \mathrm{~mm}$ for aqueous extract, and chloroform extracts showed no zone of inhibition. The ampicillin (positive control) showed the inhibition zone of $30 \mathrm{~mm}$. DMSO (negative control) showed no zone against the S. aureus. In case of E. coli bacteria, a zone of inhibition of $18.5 \mathrm{~mm}$ was observed for methanol extract, $10 \mathrm{~mm}$ for ethyl acetate extract, and $9 \mathrm{~mm}$ for aqueous extract. Chloroform extract showed no zone of inhibition. The ampicillin (positive control) showed the inhibition zone of $10 \mathrm{~mm}$. DMSO (negative control) showed no zone of inhibition (Fig. 2 and Table 3 ).

In the present study, we found that methanolic extract of $A$. indica leaves showed more antibacterial activity as compared to that of chloroform, ethyl acetate, and aqueous extracts. The increasing order of antibacterial activity against $S$. aureus is ethyl acetate<aqueous extract $<$ methanolic extract, while in case of $E$. coli, aqueous extract $<$ ethyl acetate $<$ methanolic extract.

\section{In vitro antioxidant activity}

A. indica leaf extract exhibited good antioxidant activities in comparison to ascorbic acid. $\mathrm{IC}_{50}$ value (half maximal inhibitory concentration) indicates how much of a particular drug or other substance is required to inhibit a given biological process.

\section{DPPH radical scavenging activity}

In DPPH radical scavenging activity, the results showed that percentage inhibition increased with increasing concentration from $2.5 \mu \mathrm{g} / \mathrm{ml}$ to $10 \mu \mathrm{g} / \mathrm{ml}$. DPPH antioxidant assay is based on the ability of a stable free radical, to decolorize in the presence of antioxidants. The DPPH radical contains an odd electron at $517 \mathrm{~nm}$ and is visible with deep purple color. When DPPH accepts an electron donated by an antioxidant compound, it is decolorized and can be quantitatively measured from the changes in the absorbance. Free radical scavenging effect of the corresponding different $A$. indica extracts of methanol, chloroform, and aqueous extracts was determined spectrophotometrically at $517 \mathrm{~nm}$. Ascorbic acid was used as standard free radical scavenger reference compound.

DPPH radical scavenging activity $(\%)=1-A_{s} / A_{c} \times 100$

Where $A_{c}$ - Absorbance of control, $A_{s}$ - Absorbance of the test sample.

$\mathrm{IC}_{50}$ value is a measure of the effectiveness of the substance in inhibiting a specific biological or biochemical function. The $\mathrm{IC}_{50}$ is the concentration of an inhibitor where the response (or binding) is reduced by half.

In the present study, the different extracts of $A$. indica had a significant scavenging effect on the DPPH radical which was generally significantly increased with the increase in the concentration. Methanolic extract of A. indica leaves showed comparable antioxidant activity with "ascorbic acid." In general, antioxidant activity of methanolic extracts was higher than that of chloroform, ethyl acetate, and aqueous extracts (Table 4).

\section{CONCLUSION}

In the present work, we elucidated that different extracts of $A$. indica have antimicrobial activity and contain various phytochemicals and antioxidant activity. The aim of phytochemical screening is to confirm the presence of various constituents for assessing their biological activity or medicinal use. The most important of these are alkaloids, 
Table 4: The antioxidant activity of leaf extract of Azadirachta indica using DPPH assay

\begin{tabular}{llllll}
\hline Antioxidant assay & \multicolumn{4}{l}{ Half-maximal inhibitory concentration $\left(\mathrm{IC}_{\mathbf{5 0}}\right)(\boldsymbol{\mu g} / \mathrm{ml})$} & \\
\cline { 2 - 6 } & Ascorbic acid & Methanolic extract & Chloroform extract & Ethyl acetate extract & Aqueous extract \\
\hline DPPH & 1.384 & 1.737 & 5.011 & 3.040 & 2.278 \\
\hline
\end{tabular}

DPPH: 1, 1-diphenyl-2-picrylhydrazyl

saponins, steroids, phenols, flavonoids, and tannins. Preliminary phytochemical screening of methanolic, chloroform, ethyl acetate, and aqueous extracts of the leaves of $A$. indica showed the presence of phenols, tannins, flavonoids, carbohydrates, terpenoids, and alkaloids. Protein and amino acids were absent in all extracts of $A$. indica. Alkaloids are organic nitrogenous substances. These are alkaline in nature and exhibit an extraordinary array of pharmacological activities [5]. The flavonoids act as antioxidants which provide protection against free radicals that damage cells and tissues. Tannins promote healing of wounds. These are effective in diarrhea, colitis, and peptic ulcers. High flavonoid content indicates the probability of significant antioxidant potential of the $A$. indica leaves. In the present study, we found the presence of flavonoids in all different extracts of $A$. indica [6]

The antimicrobial activity of the aqueous, methanol, chloroform, and ethyl acetate extracts of $A$. indica was checked against the bacterial strains of S. aureus and E. coli. In an earlier study, Khan et al., 1987, reported that $A$. indica leaf extract had a characteristic effect on dermatophytes, especially for lower polar extracts over high polar ones. Subapriya et al., 2005, showed that A. indica leaf extract was found to have interesting inhibitory action on a wider spectrum of microorganisms including Candida albicans, Candida tropicalis, Neisseria gonorrhea, multidrug-resistant $S$. aureus, E. coli, and herpes simplex. Singh et al., 1987, showed the fungicidal and bactericidal properties of extracts from leaves [7]. Methanolic extract of $A$. indica leaves showed more antibacterial activity as compared to that of the chloroform, ethyl acetate, and aqueous extracts. The zone of inhibition against $S$. aureus was $19.5 \mathrm{~mm}$ for methanol extract, $11.5 \mathrm{~mm}$ for ethyl acetate extract, and $13 \mathrm{~mm}$ for aqueous extract, and chloroform extracts showed no zone of inhibition against $S$. aureus [8], while in case of $E$. coli bacteria, the zone of inhibition of $18.5 \mathrm{~mm}$ was observed around the methanol extract, $10 \mathrm{~mm}$ around the ethyl acetate extract, and $9 \mathrm{~mm}$ around the aqueous extract. Chloroform extract showed no zone of inhibition. The increasing order of antibacterial activity against $S$. aureus - ethyl acetate<aqueous extract $<$ methanolic extract while in case of $E$. coli - Aqueous extract<ethyl acetate $<$ methanolic extract. Methanolic extracts showed more antioxidant activity as compared to other extracts of $A$. indica. Dekha et al., 2013, also showed the antioxidant activity of methanolic extract of leaves of $A$. indica. All the plant extracts showed potent activities among the various tests. Oral care product can be developed if the active constituents responsible for the activities were analyzed [9]. The administration of the aquatic extracts of Aloe vera, Neem, and Moringa (separately/mix) played a therapeutic role against CCl4-induced liver damage by improving liver enzyme activities and antioxidant blood parameters [10]. Plant essential oils and extracts may have a role as pharmaceuticals and preservatives [11]. A. indica had shown almost equal antimicrobial activity, against all species of microbes which was taken in a study as compared to standard ofloxacin. These results indicate that the antibacterial and antifungal activity of these extracts might be due to the presence of phytochemicals, i.e., alkaloids, saponins, flavonoids, tannins, terpenoids, and amino acids [12].

\section{AUTHORS' CONTRIBUTIONS}

Gaurav Sharma (Research scholar, Shoolini University) (First and corresponding author) has designed and conducted the work keeping in view the medicinal importance of the A. indica. Other author Ankita Thakur has the analysis and framing work of the manuscript. Statistical analysis was performed by both the authors.

\section{CONFLICTS OF INTEREST}

The authors declare that they have no competing interests.

\section{REFERENCES}

1. Shirish S. Hepatoprotection study of leaves powder of $A$ indica A. Juss. Int J Pharm Sci Rev Res 2010;3:32-45.

2. Girish K, Bhat SS. Neem-a green treasure. Electron J Biol 2008;4:102-11.

3. Bhargava KP, Gupta MB, Gupta GP, Mitra CR. Anti-inflammatory activity of saponins and ot-her natural products. Indian J Med Res 1970;58:724-30.

4. Ogbuewu IP, Odoemenam VU, Obikaonu HO, Opara MN, Emenalom OO, Uchegbu IC, et al. The growing importance of neem, in agricultural, industry, medicine and environment: A review. J Med Plant 2011;5:230-45

5. Kaushik B, Chattopadhyay I, Banerjee KR, Bandyopadhyay U. Biological activities of medicinal properties of neem. Curr Sci 2002;82:1336-45

6. Mordue AJ, Nisbet AJ, Azadirachtin from neem tree Azadirachta indica: Its action against insects. An Soc Entomol Bras 2000;29:615-32.

7. Singh, UP; Singh HB, Singh RB. The fungicidal effect of neem (Azadirachta indica) extracts on some soil borne pathogens. Mycologia 1980;7:1077-93

8. Zong A, Cao H, Wang F. Anticancer polysaccharides from natural resources: A review of recent research. Carbohydr Polym 2012;90:1395-410

9. Lavanya J, Selvam S, Priya M, Jacintha P, Aradana M. Antioxidant and antimicrobial activity of selected medicinal plants against human oral pathogens. Int J Pharm Pharm Sci 2016;8:71-8

10. Salama RA, Mohamed MM, Elwahab MA, Shakweer MM. Assessment effect of Aloe vera, Azadirachta indica and Moringa oleifera aqueous extracts on carbon tetrachloride-induced hepatotoxicity in rats. Int $\mathrm{J}$ Pharm Pharm Sci 2016;8:83-9.

11. Hammer KA, Carson CF, Riley TV. Antimicrobial activity of essential oils and other plant extracts. J Appl Microbiol 1999;86:985-90.

12. Gupta AK, Ahirwar NK, Shinde N, Choudhary M, Rajput YS, Singh A. Phytochemical screening and antimicrobial assessment of leaves of Adhatoda vasica, Azadirachta indica and Datura stramonium. UK J Pharm Biosci 2013;1:42-7. 